\title{
Assessment of an application for touchscreen devices to record calving- related events in dairy herds and monitor personnel performance
}

\author{
A. A. Barragan, J. D. Workman, S. Bas, K. L. Proudfoot, and G. M. Schuenemann ${ }^{1}$ \\ Department of Veterinary Preventive Medicine, The Ohio State University, Columbus 43210
}

\section{ABSTRACT}

The objectives of the present study were to assess (1) the effectiveness of a calving training workshop and an application (app) for touchscreen devices to capture calving-related events, and (2) personnel compliance with calving protocols (time from birth to feeding of first colostrum and time that cows spent in labor). Calving personnel $(\mathrm{n}=23)$ from 5 large dairy farms (range: 800-10,000 cows) participated in the study. Participants received training through an on-farm workshop regarding calving management practices and functioning of the app before recording calving-related events. Pre- and posttest evaluations were administered to each participant to measure their knowledge gain and satisfaction with the workshop. Calving personnel recorded calving-related events $(\mathrm{n}=323)$ using the app for $7 \mathrm{~d}$ following training. Furthermore, the records collected with the app were used to assess missing and incorrect data and calving personnel compliance with calving management protocols (recording time that cows spent in labor and timing of feeding first colostrum to calves). Calving personnel reported that the information provided during the training was relevant (agree $=14.3 \%$ and strongly agree $=85.7 \%)$ and of great immediate use (agree $=33.3 \%$ and strongly agree $=66.7 \%)$. The presented materials and hands-on demonstrations substantially increased the knowledge level of the attendees (by 23.7 percentage points from pre- to posttest scores). The follow-up assessment with participants revealed that the app was easy to use (91.3\%) and that they would continue to use it (100\%). Frequency of incorrect $(\mathrm{r}=0.77)$ or missing $(\mathrm{r}=0.76)$ data was positively correlated with calving:personnel ratio. Furthermore, calving personnel compliance with calving protocols was significantly different within and between herds. These results substantiated the great variation in compliance with calving management protocols within and between dairy farms. Furthermore, the app may serve as a tool to monitor personnel compliance with

Received December 30, 2015.

Accepted March 21, 2016.

${ }^{1}$ Corresponding author: schuenemann.5@osu.edu first feeding of colostrum to calves and their awareness and recognition of amount of time that each cow spent in labor. This would allow decision-makers to adjust, reassign tasks, or plan the management according to actual calving rate to improve the overall quality of data (frequency of incorrect and missing data) and calf welfare (survival and performance).

Key words: dairy cattle, calving personnel, mobile application, records

\section{INTRODUCTION}

In large dairy herds, it is common to observe multiple first-calf heifers or multiparous cows calving at the same time. Although lack of communication at the time of shift change has been associated with stillbirth (Hunter et al., 2013), the effects of calving rate (number of births per unit of time) and number of workers on compliance with calving protocols and standard operating procedures (SOP) have not been documented. According to the National Animal Health Monitoring System (NAHMS), only $19.4 \%$ of dairy herds kept onfarm computer records, accounting for $56.9 \%$ of the total cow inventory in the United States (USDA, 2007). Approximately $60 \%$ of dairy operations had protocols on when to intervene during calving (for cows and heifers) and only $38.5 \%$ of dairy herds had a system for scoring calving difficulty (USDA, 2010). Furthermore, only $13 \%$ of dairy operations that hand-fed colostrum monitored immunoglobulin concentrations before feeding $(7.6 \%$ for small herds and $45.2 \%$ for large herds; USDA, 2010). It is well documented that heifers and cows experiencing dystocic births raise welfare concerns due to the reduced odds of survival for both cows and calves (Lombard et al., 2007; Schuenemann et al., 2011). Lactating cows that have previously given birth to a stillborn calf have an increased risk for uterine diseases (e.g., retention of fetal membranes, metritis; Correa et al., 1993), culling (Bicalho et al., 2007), and decreased reproductive performance (Bicalho et al., 2007). Substantial knowledge exists to prevent calvingrelated losses, but the knowledge must be translated into on-farm applications to have a meaningful effect at the animal and herd levels. Prevention of calving- 
Table 1. Description of dairy herds according to size, housing, and calving management

\begin{tabular}{|c|c|c|c|c|c|}
\hline Item $^{1}$ & \multicolumn{5}{|c|}{ Dairy herd } \\
\hline Herd size, no. & 10,000 & 2,100 & 1,200 & 1,000 & 800 \\
\hline Housing type & $\mathrm{FS}+\mathrm{DL}$ & FS & FS & $\mathrm{FS}+\mathrm{DL}$ & FS \\
\hline Length of dry-off, $d$ & 60 & 42 & 60 & 60 & 50 \\
\hline Written calving protocols & Yes & Yes & Yes & Yes & Yes \\
\hline Calving-related events recorded with app, no. & 224 & 25 & 14 & 40 & 20 \\
\hline
\end{tabular}

${ }^{1} \mathrm{~A}$ predesigned voluntary survey instrument was provided to herd owners or managers to assess the calving management practices used in their dairy operations. $\mathrm{H}=$ Holstein cows, $\mathrm{H} \times \mathrm{J}=$ crossed Holstein and Jersey cows, FS = freestall barn, and DL = dry-lot barn. Herd A had 1 maternity facility and postpartum cows were distributed to 3 contiguous large dairy herds.

${ }^{2}$ All employees worked 6 consecutive days and rested $1 \mathrm{~d}$.

related losses at the herd level requires a constant effort with effective coordination of the animals, feed and water, environment and facilities, as well as personnel.

In dairy herds, protocols and SOPs are essential management tools for guiding decisions and criteria used for diagnosis and treatment of specific health conditions (e.g., metritis, mastitis) as well as to standardize management practices (e.g., milking routine, colostrum administration to calves). For instance, a written protocol provides information on what to do (e.g., treatment for a specific disease) and the SOP within the protocol describes, systematically, how to do it (operational steps and resources needed to perform a given protocol). At calving, dairy personnel are often responsible for assisting cows experiencing dystocic births and feeding colostrum to newborn calves. Under field conditions, personnel must follow the written protocols and keep accurate records. Dairy producers, consultants, and veterinarians often troubleshoot calving-related losses (e.g., stillbirth) within herds; however, the lack of meaningful records makes it difficult to implement corrective measures. Implementing an effective recordkeeping system at the cow and herd level is essential, not only to monitor the overall herd performance over time, but also to make any necessary management adjustments. The objectives of the present study were to assess: (1) the effectiveness of a calving training workshop and an application (app) for touchscreen devices to capture calving-related events, and (2) personnel compliance with calving protocols (time from birth to feeding of first colostrum and time that cows spent in labor).

\section{MATERIALS AND METHODS}

\section{Animals and Facilities}

The study was conducted using 5 large Holstein dairy herds (800-10,000 cows) located in Colorado and Ohio
(Table 1). A TMR was offered once $(\mathrm{n}=3)$ or twice per day $(n=2)$ to pre- and postpartum cows. Pregnant cows and replacement heifers were housed separately in freestall barns $(\mathrm{n}=3)$ or in freestall barns with access to a contiguous dry lot $(\mathrm{n}=2)$. Pregnant animals were grouped approximately $21 \mathrm{~d}$ before their expected calving date and moved into prepartum pens. The prepartum pens included freestalls with sand bedding (n $=3$ ) or loose straw pens with access to a dry lot (n $=2)$. Calving personnel $(\mathrm{n}=23)$ monitored all cows and replacement heifers for signs of imminent birth. Animals showing imminent signs of birth were moved into a contiguous single straw maternity pen $(\mathrm{n}=3)$ or into a separate grouped loose-straw dry lot $(n=2)$ until birth.

\section{Educational Training}

Calving personnel $(\mathrm{n}=23)$ attended a training workshop for best calving management practices (described by Schuenemann et al., 2013). During training, participants also learned how to assess and record BCS, using a 5-point scale (Ferguson et al., 1994), and calf vigor, using a 4-point scale (modified from Murray et al., 2015). In addition to the traditional content, personnel learned how to correctly use the app for touchscreen devices. The training workshop consisted of an oral presentation $(\sim 1 \mathrm{~h})$ followed by hands-on demonstrations and supervised practice $(\sim 2 \mathrm{~h})$. For the portion of the workshop dedicated to the app, the following areas were covered: (1) app login screen, (2) description and sequence of calving-related events, (3) the color-coded alarm associated with amount of time that cows were in labor, and (4) the information associated with colostrum administration. Immediately following completion of the workshop, calving personnel had the opportunity to record calving-related events using the app for 7 d. During this period, a member of the research team 
Table 2. Summary of frequency (percentages in parentheses) of the total responses per statement on the educational materials and content of the calving management workshop

\begin{tabular}{|c|c|c|c|c|c|}
\hline Educational materials and content ${ }^{1}$ & $\begin{array}{l}\text { Strongly } \\
\text { disagree }\end{array}$ & Disagree & $\begin{array}{c}\text { Neither disagree } \\
\text { nor agree }\end{array}$ & Agree & $\begin{array}{c}\text { Strongly } \\
\text { agree }\end{array}$ \\
\hline 1. Helped me better understand the issue surrounding this topic & $0(0)$ & $0(0)$ & $2(9.5)$ & $1(4.8)$ & $18(85.7)$ \\
\hline 4. Were easy to understand & $0(0)$ & $0(0)$ & $0(0)$ & $5(23.8)$ & $16(76.2)$ \\
\hline 5. Will be of great immediate use to me & $0(0)$ & $0(0)$ & $0(0)$ & $7(33.3)$ & $14(66.7)$ \\
\hline 6. Stimulated me in wanting to learn & $0(0)$ & $0(0)$ & $0(0)$ & $6(28.6)$ & $15(71.4)$ \\
\hline
\end{tabular}

${ }^{1}$ This voluntary evaluation instrument was provided to participants to assess the effectiveness of the program and benefit to participants at the conclusion of the workshop. The evaluation instrument was adapted from the Evaluation of Effective Extension Teaching instrument (form II), The Ohio State University Extension (Spiegel, 1992).

was available at all times either in person or by mobile phone to monitor data entries and provide any additional clarification on using the app.

\section{Evaluation of the Calving Management Workshop and App}

For the calving management workshop, 2 evaluation instruments were used to measure knowledge change and participants' satisfaction. Predesigned pre- and posttests of knowledge were used to assess the knowledge gain of calving personnel (Schuenemann et al., 2013). Briefly, the tests of knowledge consisted of 5 multiple-choice questions regarding the information provided during the workshop and were administered before and after the presentation (described by Schuenemann et al., 2013). The tests of knowledge were voluntary and anonymous; thus, scores were aggregated and individual improvement was not possible to assess. Participants' satisfaction with the workshop (i.e., educational materials) was assessed using the standardized Evaluation of Effective Extension Teaching form (Table 2; Spiegel, 1992). Additionally, to measure participants' satisfaction with the app, a follow-up assessment was conducted at the end of the study period to capture the reactions of calving personnel concerning the overall usefulness of the app (Table 3). These evaluation instruments were reviewed by the Office of Responsible Research Practices at The Ohio State University, and determined to be exempt from review by the internal review board. Furthermore, completion of the evaluation instruments was voluntary and conducted anonymously.

\section{Description of the Calving App}

The eCalving app was developed by Veterinary Extension at The Ohio State University and is available for Android devices free of charge at www.ecalving. com. The app was designed to capture calving-related events and monitor personnel performance with calving protocols. The app has 3 main sections: (1) calving, (2) newborn calf, and (3) colostrum. The components of the app include (1) login screen, (2) capture of selected calving-related information for both dam and calf (e.g., parity, breed, BCS, hygiene of perineum, calving ease, sex of calf, calf presentation, personnel), (3) rolling list of active cows with an alarm to monitor calving progress and the amount of time that each cow is in labor, (4) rolling list of active calves (single or multiple) within

Table 3. Summary of responses (frequency, with percentages in parentheses) regarding the follow-up assessment of participants $(\mathrm{n}=23)$ with the overall application for calving management

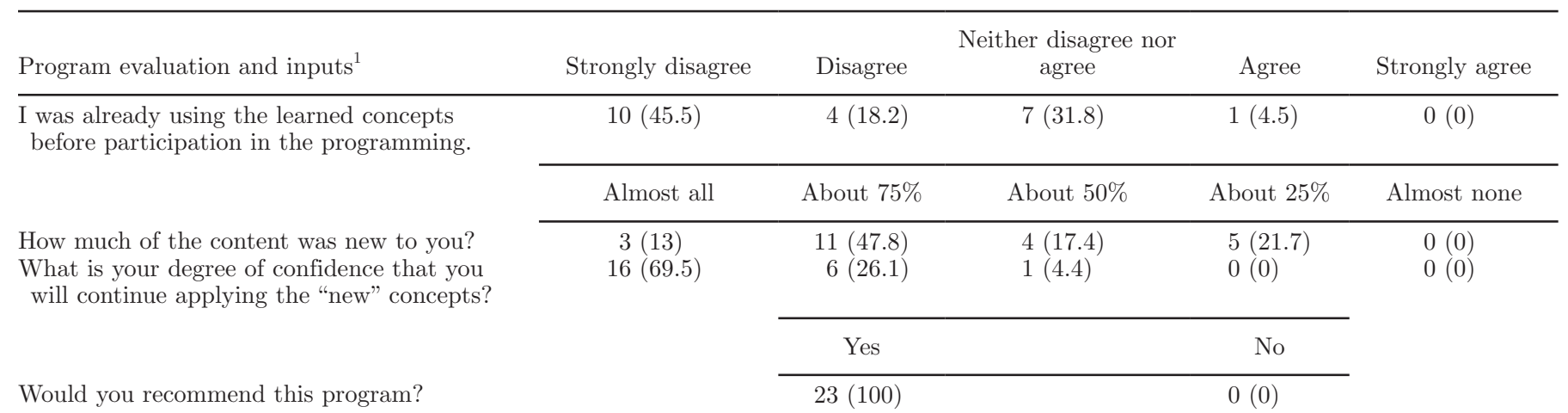

\footnotetext{
${ }^{1}$ This voluntary evaluation instrument was provided to participants to assess the satisfaction of participants with the overall calving management
} workshop at the conclusion of the educational training. 
$24 \mathrm{~h}$ after birth, (5) colostrum administration to the calf (measuring quality and quantity, as well as time of administration to the calf after birth), (6) calf vigor and birth weights, and (7) calving personnel identification that performed the tasks. Each time an event was entered, the date, time, and username (personnel ID) were automatically recorded by the app. The rolling list of active cows was composed of prepartum animals that were entered into the app and each remained on the list until parturition was completed. The rolling list of active calves was composed of recently born calves that were entered into the app, and each remained on the list for a period of $24 \mathrm{~h}$ after birth.

\section{Recording of Calving-Related Events}

Immediately following training and hands-on practice, calving personnel began capturing calving-related events $(\mathrm{n}=323)$ for a period of $7 \mathrm{~d}$. The app was available on a handheld tablet (Galaxy Tab 3, SM-T210R, Samsung, Vietnam) with a rugged protective cover. Calving personnel walked the prepartum pens every 1 $\mathrm{h}$ looking for heifers and cows with imminent signs of birth such as appearance of amniotic sac (AS) or feet of the calf outside the vulva. Once personnel identified a cow with AS or feet of the calf outside the vulva, the cow identification number was captured as "new calving" and added to the list of active cows. The app recognizes this entry as "time 0" of stage II of labor; thus, personnel could monitor the amount of time that each cow was in labor using a color-coded alarm (green $\leq 1 \mathrm{~h}$, yellow $=1-2 \mathrm{~h}$, and red $\geq 2 \mathrm{~h}$ ). Once calving was completed, information regarding the degree of difficulty at calving using a 5-point scale (adapted from Lombard et al., 2007; Schuenemann at al., 2011) and the newborn calf were recorded. Newborn calves were automatically transferred to a list of active calves and the information for each calf (e.g., calf ID, sex, and colostrum) was recorded. At the end of each work shift, the information recorded by the app was sent to the cloud (Internet-based network to store and access data remotely) for data storage.

\section{Assessment of Data and Personnel Performance}

The frequencies of incorrect and missing information were assessed to determine personnel compliance with calving protocols. An incorrect event was defined as a captured data point that deviated from the defined event (incorrect cow identification, cows with BCS $\leq 1$, time that each cow spent in labor $<20 \mathrm{~min}$, colostrum administration to calf of $0 \mathrm{~L}$ ). Under normal conditions, first appearance of the AS to birth is completed between 21 and 70 min in Holstein cattle (Schuenemann et al., 2011); thus, any cow that spent $<20 \mathrm{~min}$ in labor was considered incorrect. Missing events were obtained by counting the number of calving events (data points) not entered into the app. The calving:personnel ratio was determined as the number of births per worker within the shift during a 24 -h period (Table 1 ).

Performance of personnel was assessed by their compliance with calving protocols (recording the amount of time that each cow is in labor and time from birth to first calf feeding of colostrum) using data collected by the app. Time in labor is an important metric that personnel must monitor to determine the appropriate time for intervention during difficult births. For all dairy herds, the time that each cow spent in labor was defined during the educational training as the duration from the appearance of the AS or feet of the calf outside the vulva to birth; thus, this information was automatically captured by the app. In addition, participants learned, during the training workshop, to administer colostrum within $3 \mathrm{~h}$ following calf birth; thus, this event was also recorded by workers using the app. Therefore, compliance with both protocols was used to assess the consistency of personnel performing these tasks.

\section{Statistical Analyses}

Quantitative and qualitative data were collected using predesigned evaluation instruments. A Likert-type scale (Spiegel, 1992) was used to acquire quantitative data and was reported as frequencies and percentages. Furthermore, qualitative feedback from calving personnel regarding the calving workshop and the use of the app were summarized and reported in the text. The tests of knowledge were voluntary and anonymous. Therefore, the pre- and posttest scores were considered independent and analyzed using GLIMMIX procedure of SAS (SAS Institute Inc., Cary, NC). A model procedure that included tests of knowledge was used to compare differences among groups (pre- and posttest).

Calving-related events $(\mathrm{n}=323)$ were recorded by calving personnel using the app, and the time that cows spent in labor for unassisted births and the time from birth to first colostrum administration were analyzed. Normality of data was assessed using the Shapiro-Wilk test using PROC UNIVARIATE (SAS Institute Inc.). The effect of personnel and herd on time spent in labor ( $\mathrm{h}$; mean and range) and the time from birth to feeding colostrum ( $\mathrm{h}$; mean and range) were analyzed using the MIXED procedure (SAS Institute Inc.). A model procedure that included time spent in labor and time from birth to feeding colostrum was used to compare differences among personnel within herds. Herd was included as a random effect. The frequency 
of incorrect and missing data were correlated with the calving:personnel ratio using PROC CORR (SAS Institute Inc.) accounting for the effect of herd. A $P$-value $<$ 0.05 was considered statistically significant.

\section{RESULTS}

The description of dairy herds with regard to herd size, breed of cows, housing type, management practices (length of dry period and written calving protocols), and personnel is provided in Table 1. In total, 323 calving-related events from 5 dairy herds were recorded by 23 calving personnel (Table 1 ).

\section{Assessment of the Calving Workshop and App}

Overall, calving personnel knowledge increased $(P<$ 0.0001) after the calving management workshop (Table 4). Participants reported that the information provided during the calving workshop was relevant (strongly agree $=85.7 \%$ and agree $=14.3 \%)$ and of great immediate use (strongly agree $=66.7 \%$ and agree $=33.3 \%$; Table 2). Furthermore, the attendees stated that the concepts learned in the workshop were new $(78.2 \%$ indicated that $\geq 50 \%$ of concepts were new), showed a great degree of confidence in using the new practices (almost all $=69.5 \%$ and about $75 \%=26.1 \%$ ), and would recommend the workshop (100\%; Table 3$)$. Participants did not give any negative feedback regarding the calving workshop or app. Moreover, participants reported that the app was easy to use $(91.30 \%)$, they liked it $(95.65 \%)$ and would like to continue using it (100\%). During the training workshop and follow-up assessment, personnel also indicated that the colorcoded alarm to track the time heifers and cows spent in labor and the list of born calves served as reminders of calving protocols within the farm team (e.g., between workers at the time of work shift, when to feed first colostrum to calves, when to call for help).

Table 4. Percentage of correct responses to pre- and posttest questions from a comprehensive education workshop on calving management for dairy personnel ${ }^{1}$

\begin{tabular}{lccc}
\hline Question & Pretest & Posttest & $P$-value \\
\hline 1 & 60.0 & 83.9 & 0.03 \\
2 & 70.9 & 90.3 & 0.05 \\
3 & 64.5 & 100 & 0.0001 \\
4 & 73.3 & 93.5 & 0.03 \\
5 & 70.9 & 90.3 & 0.05 \\
Overall $^{2}$ & 67.9 & 91.6 & $<0.0001$ \\
\hline
\end{tabular}

${ }^{1}$ Percentage of correct answers was calculated from 23 pre- and posttests.

${ }^{2}$ Percentage of correct answers was calculated taking into account the total number of tests obtained per workshop using a weighted average.

\section{Assessment of Data and Personnel Performance}

In the present study, frequencies of incorrect $(\mathrm{r}=$ $0.77 ; P<0.0003)$ and missing $(\mathrm{r}=0.76 ; P<0.001)$ data were both positively correlated with calving:personnel ratio (Figure 1). Personnel and herd were significantly associated $(P<0.05)$ with the mean time that cows spent in labor and time from birth to colostrum administration (Figures 2 and 3). For unassisted births, the mean time that cows spent in labor was $\leq 2 \mathrm{~h}$ for 18 workers, whereas 4 workers had a mean time in labor $>2 \mathrm{~h}$ (Figure 2). Furthermore, 7 workers from 3 different herds recorded at least 1 cow or heifer that spent 6 to $18 \mathrm{~h}$ in labor for unassisted births (Figure 2). All personnel fed colostrum within the first $3 \mathrm{~h}$ of birth, but 2 workers from 2 different herds had the greatest time variation (range) in feeding colostrum to calves (Figure 3).

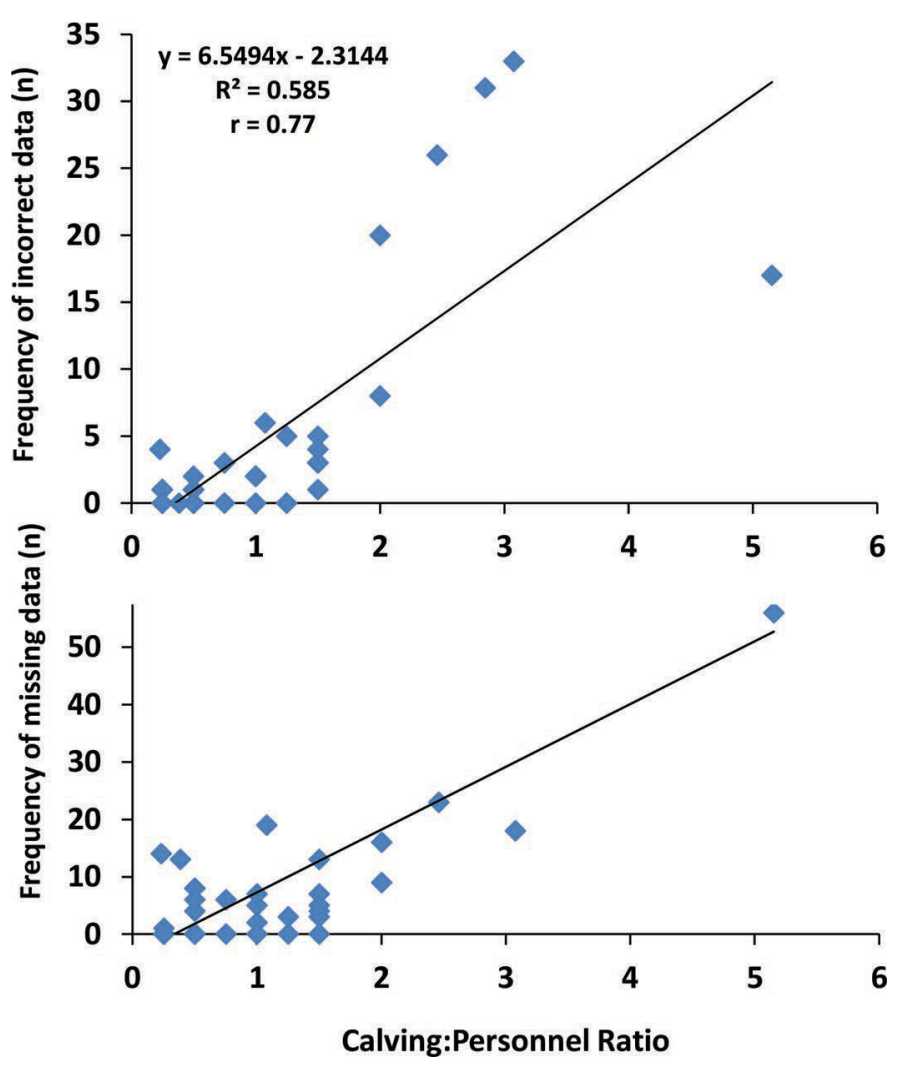

Figure 1. Scatter plots showing the association of calving:personnel ratio with missing or incorrect data. The frequency of missing events was obtained by counting the number of missing data points (entries) for each calving event. An incorrect event was operationally defined as a captured data point that deviated from the defined event (incorrect cow identification, cows with $\mathrm{BCS} \leq 1$, time that cows spent in labor $<20 \mathrm{~min}$, colostrum administration to calf of $0 \mathrm{~L}$ ). The calving:personnel ratio was determined as the number of births per worker within the shift. Incorrect data $=(6.5494 \times$ calving:personnel ratio $)-2.3144$. Missing data $=(10.935 \times$ calving:personnel ratio $)-$ 3.6593. Color version available online. 


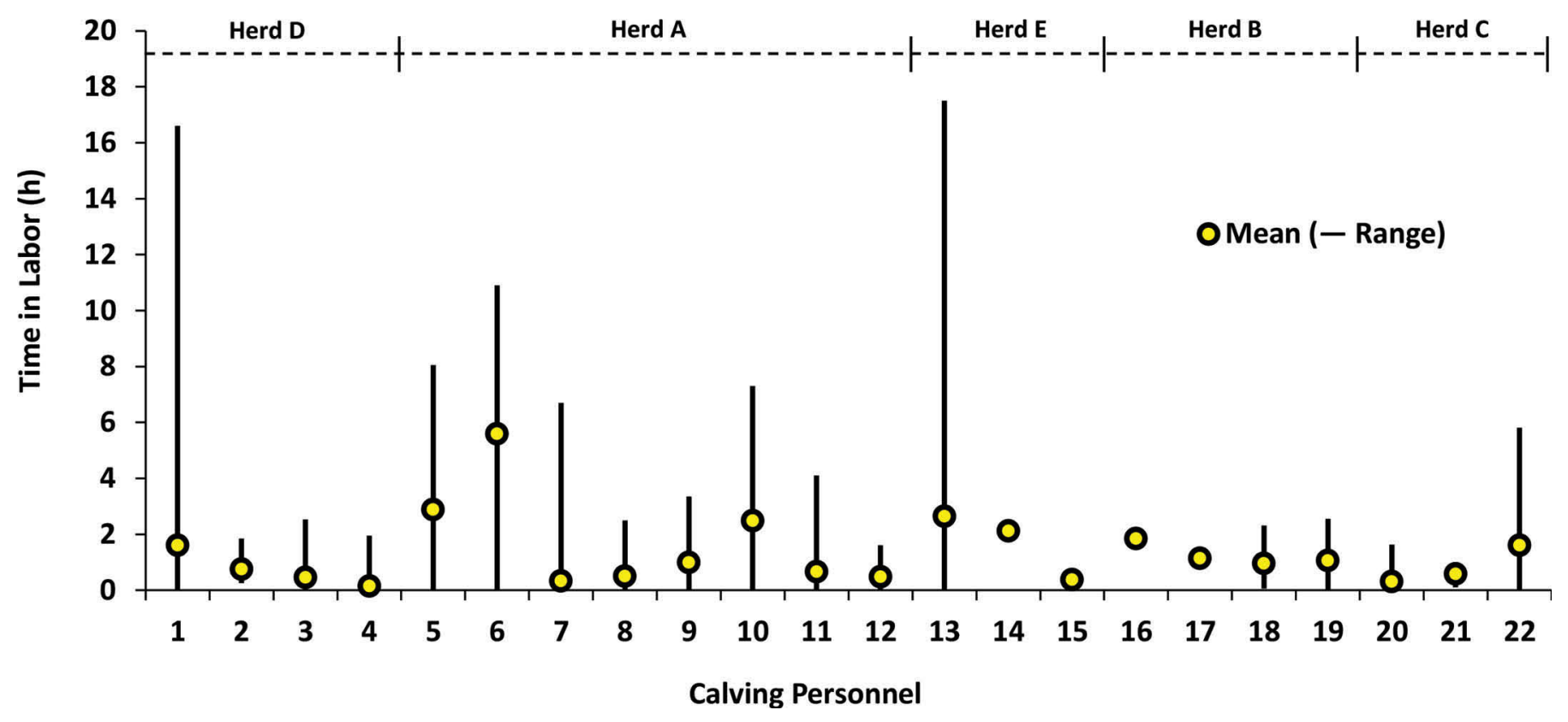

Figure 2. Mean (range) distribution of time that cows spent in labor (h) recorded by calving personnel. Mean (range) time that cows spent in labor (h) was assessed (time from the appearance of amniotic sac or feet of the calf outside the vulva to birth) for each unassisted calving (score of 1) recorded by personnel within herds; 22 calving personnel were included. A worker with only 1 calving entry was not included in the analysis. Within herd D: workers $1,2,3$, and $4\left(1.62^{\mathrm{a}}, 0.76^{\mathrm{b}}, 0.46^{\mathrm{b}}\right.$, and $0.16^{\mathrm{b}} \mathrm{h}$, respectively: $\left.P=0.04\right)$. Within herd A: workers $5,6,7,8$, $9,10,11$, and $12\left(2.89^{\mathrm{b}}, 5.60^{\mathrm{a}}, 0.34^{\mathrm{c}}, 0.51^{\mathrm{c}}, 1.01^{\mathrm{bc}}, 2.49^{\mathrm{b}}, 0.67^{\mathrm{bc}}\right.$, and $0.49^{\mathrm{bc}} \mathrm{h}$, respectively; $\left.P=0.004\right)$. Within herd E: workers 13,14, and 15 $\left(2.65^{\mathrm{a}}, 2.13^{\mathrm{a}}\right.$, and $0.39^{\mathrm{b}} \mathrm{h}$, respectively; $\left.P=0.01\right)$. No differences were observed among workers within herds $\mathrm{C}(P=0.37)$ and $\mathrm{B}(P=0.75)$. The overall mean time that cows spent in labor (h) for herds D, A, E, B, and C $\left(0.80^{\mathrm{b}}, 2.23^{\mathrm{a}}, 1.29^{\mathrm{ab}}, 1.13^{\mathrm{ab}}\right.$, and $0.92^{\mathrm{ab}} \mathrm{h}$, respectively; $\left.P=0.007\right)$. Color version available online.

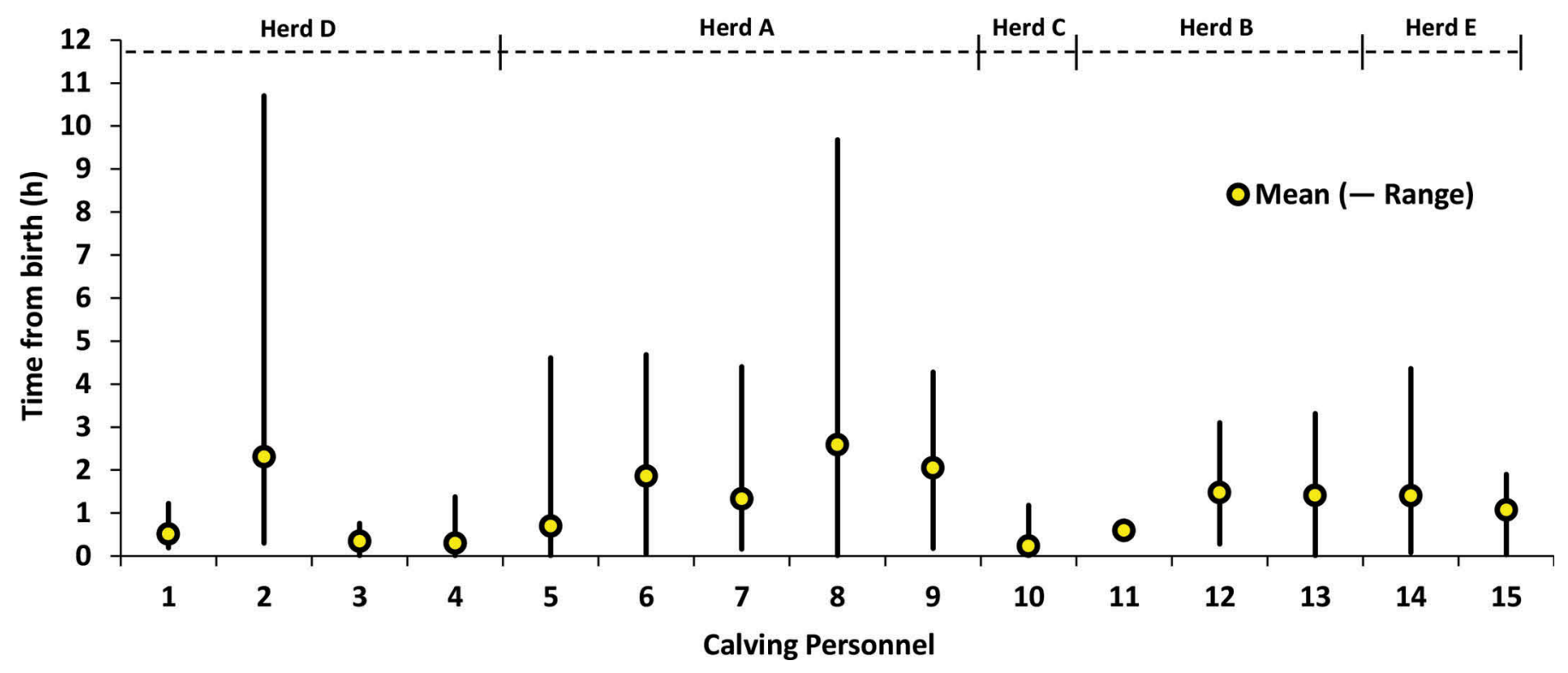

Figure 3. Mean (range) distribution of time (h) from calf birth to feeding first colostrum recorded by personnel. The mean (range) time (h) from calf birth to the first feeding of colostrum. Only calving personnel responsible for colostrum administration that fed 2 or more calves ( $\mathrm{n}$ $=15$ ) were included in the analysis; 3 workers had only 1 colostrum administration entry and were not included in the analysis. Within herd D: workers $1,2,3$, and $4\left(0.51^{\mathrm{b}}, 2.31^{\mathrm{a}}, 0.34^{\mathrm{b}}\right.$, and $0.30^{\mathrm{b}} \mathrm{h}$, respectively; $\left.P=0.01\right)$. Within herd A: workers $5,6,7,8$, and $9\left(0.70^{\mathrm{b}}, 1.86^{\mathrm{ab}}, 1.33^{\mathrm{ab}}\right.$, $2.59^{\mathrm{a}}$, and $2.05^{\mathrm{ab}} \mathrm{h}$, respectively: $\left.P=0.004\right)$. Within herd $\mathrm{C}$ : worker $10(0.23 \mathrm{~h})$. No differences were observed among workers within herds B $(P=0.67)$ and $\mathrm{E}(P=0.55)$. The overall mean time $(\mathrm{h})$ from calf birth to colostrum administration for herds $\mathrm{D}, \mathrm{A}, \mathrm{C}, \mathrm{B}$, and $\mathrm{E}\left(0.49^{\mathrm{b}}, 1.71^{\mathrm{a}}\right.$, $0.23^{\mathrm{b}}, 1.30^{\mathrm{ab}}$, and $1.23^{\mathrm{ab}} \mathrm{h}$, respectively; $\left.P<0.0001\right)$. Color version available online. 


\section{DISCUSSION}

The primary findings of the present study are that (1) the calving workshop increased personnel knowledge; (2) the frequencies of incorrect and missing data were significantly associated with calving:personnel ratio; and (3) the app served as a tool to monitor personnel compliance with calving protocols. The overall results of the pre- and posttests from the calving workshop indicated that participants gained new calving management knowledge. Regardless of dairy herd size, a recent study showed similar knowledge gain by participants about calving management practices (Schuenemann et al., 2013). Furthermore, calving personnel reported that the information provided during the training was relevant and of great immediate use. Under field conditions, recognizing the stages of parturition (question 1), the signs of normal and difficult births (questions 2 and 4 ), and correct placement of obstetric chains for assisted births (question 3) are critical skills to determine both the appropriate time for intervention and how to assist difficult births to reduce the risk for stillbirth or injury to the dam (Schuenemann et al., 2013). Also, the timing and amount of colostrum to be fed to the newborn calf (question 5) is critical for calf survival and development (Godden, 2008). In the follow-up assessment (immediately after the study period), participants reported that they liked using the app, it was easy to use, and they would recommend its continued use. According to dairy personnel, these results suggest that the app is a user-friendly tool that allows automatic data transfer under field conditions. Such user-friendly applications have been used by farmers and veterinarians to capture antimicrobial use in dairy herds (Menéndez González et al., 2010); however, this is, to our knowledge, the first time that an app has been used to assess calvingrelated events under field conditions.

The present study showed that increased calving:personnel ratio was directly associated with increased frequencies of incorrect and missing records. For those producers who want to minimize the frequency of incorrect and missing records ( $<10$ points), a calving:personnel ratio of $<1.3$ would be needed. As an example, a 2,000-cow herd with an average of 5 births/day would need at least a total of 4 workers ( 5 births $/ 4$ workers $=1.369$ ratio) every 24 -h period (e.g., 2 workers per 12-h shift) to take care of periparturient cows and feed colostrum to calves while keeping the frequencies of missing and incorrect data below 10 points. This calculation assumes that pregnant cows and replacement heifers are calving evenly across time and that personnel are also responsible for other tasks (e.g., cleaning stalls or feeding cows). However, it is common to observe large variation over time in calving frequency for large dairy herds (e.g., 1-10 births per day for a 2,000-cow herd). There is a fine balance between keeping accurate calving-related records and the appropriate number of workers needed to perform the expected calving tasks. Although assigning more workers to calving tasks has obvious economic implications for dairy herds, the potential benefits in terms of compliance with protocols, data quality, and calf survival warrant further research. Also, the app has the ability to automatically capture the date and time (using the internal device calendar) when calving-related events are recorded. This avoids common mistakes when recording events, as observed with on-farm written paper records. Menéndez González et al. (2010) reported that the handwritten paper records had a greater proportion of errors compared with on-farm computer (e.g., Excel spreadsheet) and Internet-based applications. The effect of work shift length (e.g., 8, 10, or $12 \mathrm{~h}$ ) was not investigated in the present study; thus, further investigation is needed to assess personnel performance, turnover, number of consecutive days worked, overlapping shifts, workload (multitasking), number of relief workers needed, and how the combination of these factors may affect the quality of records and calf survival.

Personnel with poor or no training and high turnover at the farm level (Mugera and Bitsch, 2005) may affect the quality of data due to a lack of understanding of what data points are critical to record over time. Espetvedt et al. (2013) reported $10 \%$ missing data in the Norwegian national database compared with individual on-farm cow health cards. Furthermore, Menéndez González et al. (2010) found that an Internet-based application improved the data quality (accuracy in recording animal ID) compared with handwritten paper and on-farm computer records (Excel spreadsheet). It is important to note that most calving personnel indicated that the app was easy to use, but the proportion of personnel who own a smartphone was not assessed in the present study. Furthermore, dairy personnel who have previously been exposed to smartphones or tablets may have a better understanding of the functionality of an app, which in turn may improve the quality of data. The timing and accuracy of data recording always depends on the willingness of the individual recording the information regardless of the recordkeeping method used. To the best of our knowledge, this is the first study to report a significant association between quality of data (frequencies of incorrect and missing data points) about calving management and calving:personnel ratio in dairy herds. In addition to weekly or monthly wages, some dairy herds offer economic incentives (e.g., bonuses) that are paid based on performance of individual workers. Because assessing personnel performance relies heavily on honesty, trust, and objectively, the app 
could be useful as a management tool to provide key performance metrics on those individuals executing the protocols.

The app served as a tool to monitor personnel compliance with 2 key protocols: time from birth to colostrum administration and time that cows spent in labor. Although personnel received the same calving management training, the app revealed that some workers had great variation in timing from birth to colostrum administration, whereas other workers showed more consistent performance over time. The prevalence of failure of passive transfer (FPT) of immunity is around $19.2 \%$ on US dairy farms (Beam et al., 2009) and $37.1 \%$ in Ontario, Canada (Trotz-Williams et al., 2008). Feeding the appropriate amount $(3.8 \mathrm{~L})$ and quality of colostrum immediately after birth provides adequate consumption of $\operatorname{IgG}$, avoiding FPT (IgG $<10 \mathrm{mg} / \mathrm{mL}$; Calloway et al., 2002). One of the greatest risk factors contributing to preweaned calf mortality is FPT, which is associated with 39 to $50 \%$ of preweaned calf mortality (Margerison and Downey, 2005). The major factor affecting IgG absorption is the time from birth to colostrum administration because the absorption of IgG is optimal within the first $4 \mathrm{~h}$ after birth and declines significantly after $6 \mathrm{~h}$ (Godden, 2008). Although the prevalence of FPT in calves was not assessed in the present study, monitoring the time from birth to colostrum administration may serve as a key performance metric for FPT and subsequent calf survival and performance. All workers had a mean time from birth to first colostrum administration of $<3 \mathrm{~h}$. However, 2 workers from 2 different herds had similar mean times (2.31 and $2.59 \mathrm{~h}$ ) but large variation in colostrum feeding time $(0.3-10.7 \mathrm{~h}$ and $0.1-9.7 \mathrm{~h}$, respectively). The consistency of colostrum administration over time (all calves receiving adequate quality and quantity of colostrum within the optimum time) may explain, at least in part, the observed variation of FPT in calves and the subsequent survival and performance (Godden, 2008).

In large dairy herds, it is common to observe multiple first-calf heifers or multiparous cows calving at the same time. Being able to recognize the signs of imminent birth is critical to determine the amount of time that the first-calf heifer or cow spends in labor (from the appearance of AS or feet of the calf outside the vulva to birth) and the appropriate time for intervention during difficult births (Schuenemann et al., 2013). The birth of the calf is a natural process that is divided into 3 stages (Noakes et al., 2001) and, under normal conditions, it progresses gradually from one stage to the next. The second stage of labor is characterized by the appearance of the AS or feet of the calf outside the vulva and evident abdominal contractions, and the second stage ends with the delivery of the calf (Noakes et al., 2001; Schuenemann et al., 2011). Under normal conditions, the time from the appearance of the AS outside the vulva to birth is $70 \mathrm{~min}$ for Holstein dairy cows (Schuenemann et al., 2011), and a second-stage duration $>2 \mathrm{~h}$ has been associated with an increased proportion of stillbirths (Gundelach et al., 2009; Schuenemann et al., 2011). Furthermore, these factors are often time compromised around the shift change of personnel ( $1 \mathrm{~h}$ before and after), with a subsequent increase in stillbirth prevalence (Hunter et al., 2013). The mean time in labor for unassisted births was under $2 \mathrm{~h}$ for 18 workers, whereas 4 workers had a mean time in labor $>2 \mathrm{~h}$. Also, it is important to note the variation (range) of time in labor recorded for unassisted births among workers within and between herds. For instance, worker 1 had a mean time in labor of $1.6 \mathrm{~h}$ with a range of 0 to $16.6 \mathrm{~h}$, whereas worker 2 had a mean of $2.6 \mathrm{~h}$ and a range of 0 to $17.5 \mathrm{~h}$. First-calf heifers or multiparous cows with short times in labor indicate that personnel missed "time 0" (appearance of AS or feet of the calf appearance outside the vulva) and the animals were likely well advanced into the second stage of labor or the calf was already born. The frequency of observation (calving personnel walking the pen and actually observing cows every $1 \mathrm{~h}$ ) is critical to determine the onset of the AS or feet of the calf outside the vulva (Schuenemann et al., 2013). In large dairy herds, calving rate (the number of births per unit of time) and personnel available per work shift may influence compliance with calving protocols, which in turn may affect calf survival due to late or no intervention. During the training workshop and follow-up assessment, personnel indicated that the color-coded alarm to track the time heifers and cows spent in labor and the list of calves born served as reminders of calving protocols within the farm team (e.g., between workers at the time of work shift, when to feed first colostrum to calves, when to call for help). Monitoring the time that cows spent in labor may serve as a key performance metric to assess personnel compliance with protocols (and prevent procedural drift), as well as to adjust the number of personnel needed according to the actual calving rate (workload). The association between personnel compliance with "time in labor" and stillbirth needs further research because of its implications for cow-calf survival and welfare.

\section{CONCLUSIONS}

A calving management workshop substantially increased personnel knowledge and provided relevant information with immediate field application. The app accurately recorded calving-related events and, according to personnel, was easy to use. Additionally, the app 
may serve as a tool to monitor personnel performance by assessing their compliance with calving protocols such as time from calf birth to feeding first colostrum and time that cows spend in labor. This would allow decision-makers to adjust, reassign tasks, or preplan calving management according to actual calving rate to improve the overall quality of data (frequencies of incorrect and missing data) and calf welfare (survival and performance).

\section{ACKNOWLEDGMENTS}

The authors thank the dairy farms for providing the animals used in the present study. Special thanks to the farm owners and calving personnel for providing valuable comments about the app capabilities. This project was partially supported by Veterinary Extension at The Ohio State University.

\section{REFERENCES}

Beam, A. L., J. E. Lombard, C. A. Kopral, L. P. Garber, A. L. Winter, J. A. Hicks, and J. L. Schlater. 2009. Prevalence of failure of passive transfer of immunity in newborn heifer calves and associated management practices on US dairy operations. J. Dairy Sci. 92:3973-3980.

Bicalho, R. C., K. N. Galvão, S. H. Cheong, R. O. Gilbert, L. D. Warnick, and C. L. Guard. 2007. Effect of stillbirth on dam survival and reproduction performance in Holstein dairy cows. J. Dairy Sci. 90:2797-2803.

Calloway, C. D., J. W. Tyler, R. K. Tessman, D. Hostetler, and J Holle. 2002. Comparison of refractometers and test endpoints in the measurement of serum transfer status in calves. J. Am. Vet. Med. Assoc. 221:1605-1608.

Correa, M. T., H. Erb, and J. Scarlett. 1993. Path analysis for seven postpartum disorders of Holstein cows. J. Dairy Sci. 76:1305-1312.

Espetvedt, M. N., O. Reksen, S. Rintakoski, and O. Østerås. 2013. Data quality in the Norwegian dairy herd recording system: Agreement between the national database and disease recording on farm. J. Dairy Sci. 96:2271-2282.

Ferguson, J. D., D. T. Galligan, and N. Thomsen. 1994. Principal descriptors of body condition score in Holstein cows. J. Dairy Sci. 77:2695-2703.

Godden, S. 2008. Colostrum management for dairy calves. Vet. Clin. North Am. Food Anim. 24:19-39.
Gundelach, Y., K. Essmeyer, M. K. Teltscher, and M. Hoedemaker. 2009. Risk factors for perinatal mortality in dairy cattle: Cow and foetal factors, calving process. Theriogenology 71:901-909.

Hunter, A., M. G. Maquivar, S. Bas, J. D. Workman, and G. M. Schuenemann. 2013. Assessment of work shift transition of calving personnel on stillbirth in Holstein dairy cows. J. Dairy Sci. 96(ESuppl. 1):383. (Abstr.)

Lombard, J. E., F. B. Garry, S. M. Tomlinson, and L. P. Garber. 2007. Impacts of dystocia on health and survival of dairy calves. J. Dairy Sci. 90:1751-1760.

Margerison, J., and N. Downey. 2005. Guidelines for optimal dairy heifer rearing and herd performance. Pages 307-338 in Calf and Heifer Rearing - Principles of Rearing the Modern Dairy Heifer. P. C. Garnsworthy, ed. Nottingham University Press, London, UK.

Menéndez González, S., A. Steiner, B. Gassner, and G. Regula. 2010. Antimicrobial use in Swiss dairy farms: Quantification and evaluation of data quality. Prev. Vet. Med. 95:50-63.

Mugera, A. W., and V. Bitsch. 2005. Managing labor on dairy farms: a resource-based perspective with evidence from case studies. Int. Food Agribus. Rev. Assoc. 8:79-98.

Murray, C. F., D. B. Haley, T. F. Duffield, D. L. Pearl, S. M. Deelen, and K. E. Leslie. 2015. A field study to evaluate the effects of meloxicam NSAID therapy and calving assistance on newborn calf vigor, improvement of health and growth in pre-weaned Holstein calves. Bovine Pract. 49:1-12.

Noakes, D. E., T. J. Parkinson, and G. C. W. England. 2001. Dystocia and other disorders associated with parturition. Pages 205-338 in Arthur's Veterinary Reproduction and Obstetrics. 8th ed. W. B. Saunders, Philadelphia, PA.

Schuenemann, G. M., S. Bas, E. Gordon, and J. D. Workman. 2013. Dairy calving management: Description and assessment of a training program for dairy personnel. J. Dairy Sci. 96:2671-2680.

Schuenemann, G. M., I. Nieto, S. Bas, K. N. Galvão, and J. Workman. 2011. Assessment of calving progress and reference times for obstetric intervention during dystocia in Holstein dairy cows. J. Dairy Sci. 94:5494-5501.

Spiegel, M. 1992. Synthesizing evaluation: Perspectives, practices and evidence. Pages 27-37 in Proc. Am. Evaluation Assoc. 92: Extension Evaluation Education Topical Interest Group, Seattle, WA. American Evaluation Association, Fairhaven, MA.

Trotz-Williams, L. A., K. E. Leslie, and S. Peregrine. 2008. Passive immunity in Ontario dairy calves and investigation of its association with calf management practices. J. Dairy Sci. 91:3840-3849.

USDA. 2007. Dairy, 2007: Part I: References of dairy cattle health and management practices in the United States, 2007. \#N480.1007. USDA: Animal and Plant Health Inspection Service: Veterinary Service, Center for Epidemiology and Animal Health, Fort Collins, CO.

USDA. 2010. Dairy 2007: Heifer calf health and management practices on U.S. dairy operations, 2007. \#550.0110. USDA: Animal and Plant Health Inspection Service: Veterinary Service, Center for Epidemiology and Animal Health, Fort Collins, CO. 